\title{
The effect of targeting Tie2 on hemorrhagic shock-induced renal perfusion disturbances in rats
}

\author{
Anoek L. I. van Leeuwen 1,2,3, Nicole A. M. Dekker ${ }^{1,2,3}$, Paul Van Slyke ${ }^{4}$, Esther de Groot ${ }^{1}$, Marc G. Vervloet ${ }^{5}$,
} Joris J. T. H. Roelofs ${ }^{6}$, Matijs van Meurs ${ }^{7,8}$ and Charissa E. van den Brom ${ }^{1,2,9^{*}}$ (D)

\author{
${ }^{*}$ Correspondence: \\ c.vandenbrom@amsterdamumc.nl \\ ${ }^{1}$ Department of Anesthesiology, \\ Experimental Laboratory for Vital \\ Signs, Amsterdam Cardiovascular \\ Sciences, Amsterdam UMC, \\ Vrije Universiteit, De Boelelaan \\ 1117, 1081 HV Amsterdam, The \\ Netherlands \\ Full list of author information \\ is available at the end of the \\ article
}

\begin{abstract}
Background: Hemorrhagic shock is associated with acute kidney injury and increased mortality. Targeting the endothelial angiopoietin/Tie2 system, which regulates endothelial permeability, previously reduced hemorrhagic shock-induced vascular leakage. We hypothesized that as a consequence of vascular leakage, renal perfusion and function is impaired and that activating Tie2 restores renal perfusion and function.

Methods: Rats underwent $1 \mathrm{~h}$ of hemorrhagic shock and were treated with either vasculotide or PBS as control, followed by fluid resuscitation for $4 \mathrm{~h}$. Microcirculatory perfusion was measured in the renal cortex and cremaster muscle using contrast echography and intravital microscopy, respectively. Changes in the angiopoietin/Tie2 system and renal injury markers were measured in plasma and on protein and mRNA level in renal tissue. Renal edema formation was determined by wet/dry weight ratios and renal structure by histological analysis.
\end{abstract}

Results: Hemorrhagic shock significantly decreased renal perfusion $(240 \pm 138$ to $51 \pm 40, p<0.0001)$ and cremaster perfusion ( $12 \pm 2$ to $5 \pm 2$ perfused vessels, $p<0.0001)$ compared to baseline values. Fluid resuscitation partially restored both perfusion parameters, but both remained below baseline values (renal perfusion $120 \pm 58$, $p=0.08$, cremaster perfusion $7 \pm 2$ perfused vessels, $p<0.0001$ compared to baseline). Hemorrhagic shock increased circulating angiopoietin-1 ( $p<0.0001)$, angiopoietin-2 $(p<0.0001)$ and soluble Tie2 $(p=0.05)$, of which angiopoietin-2 elevation was associated with renal edema formation $(r=0.81, p<0.0001)$. Hemorrhagic shock induced renal injury, as assessed by increased levels of plasma neutrophil gelatinase-associated lipocalin (NGAL: $p<0.05)$, kidney injury marker-1 (KIM-1; $p<0.01)$ and creatinine $(p<0.05)$. Vasculotide did not improve renal perfusion ( $p>0.9$ at all time points) or reduce renal injury (NGAL $p=0.26, \mathrm{KIM}-1 p=0.78$, creatinine $p>0.9$, renal edema $p=0.08$ ), but temporarily improved cremaster perfusion at $3 \mathrm{~h}$ following start of fluid resuscitation compared to untreated rats (resuscitation $+3 \mathrm{~h}: 11 \pm 3$ vs $8 \pm 3$ perfused vessels, $p<0.05)$.

Conclusion: Hemorrhagic shock-induced renal impairment cannot be restored by standard fluid resuscitation, nor by activation of Tie2. Future treatment strategies author(s) and the source, provide a link to the Creative Commons licence, and indicate if changes were made. The images or other third party material in this article are included in the article's Creative Commons licence, unless indicated otherwise in a credit line to the material. If material is not included in the article's Creative Commons licence and your intended use is not permitted by statutory regulation or exceeds the permitted use, you will need to obtain permission directly from the copyright holder. To view a copy of this licence, visit http:// creativecommons.org/licenses/by/4.0/. 
should focus on reducing angiopoietin-2 levels or on activating Tie2 via an alternative strategy.

Keywords: Hemorrhage, Acute kidney injury, Contrast-enhanced ultrasonography, Microcirculatory perfusion, Vascular leakage, Endothelium

\section{Introduction}

Hemorrhagic shock is associated with increased mortality and organ failure [1]. In particular, acute kidney injury (AKI) is a major complication following hemorrhagic shock and contributes to prolonged hospital stay and increased mortality [2]. The incidence of AKI following hemorrhagic shock is reported up to $25 \%$, despite early control of bleeding and adequate fluid resuscitation [3]. Unfortunately, effective additional drug treatment strategies to reduce the incidence of AKI are lacking.

Sublingual microcirculatory perfusion is disturbed immediately following hemorrhagic shock $[1,4]$ and prolonged disturbances in microcirculatory perfusion are associated with multiple organ failure [1]. The renal vasculature is particularly vulnerable for acute blood flow deficits due to its high energy demand [5]. As a consequence of disturbed renal perfusion, oxygen delivery is impaired [6], which leads to disturbed renal function [7]. Although the general pathophysiology of AKI is well described, studies investigating the course of perfusion following hemorrhagic shock are limited $[8,9]$.

One of the underlying mechanisms that compromises microcirculatory perfusion is increased endothelial permeability, which results in leakage of fluid to the interstitium and edema formation. In rats, we previously showed that hemorrhagic shock-induced renal vascular leakage coincided with microcirculatory perfusion disturbances in the cremaster muscle [10]. Additionally, our group showed that plasma from traumatic hemorrhagic shock patients induced endothelial hyperpermeability, which associated with sublingual microcirculatory perfusion disturbances [11]. An important regulator of endothelial permeability is the angiopoietin/Tie2 system [12]. In healthy physiology, angiopoietin-1 binds to the tyrosine kinase receptor Tie2, resulting in phosphorylation of Tie2 and thereby maintaining endothelial barrier function [12]. Following acute inflammation, as seen during hemorrhagic shock, angiopoietin-2 is released from the Weibel-Palade bodies, which antagonistically binds to and inhibits phosphorylation of Tie2, thereby increasing endothelial permeability [13]. Increased levels of plasma angiopoietin-2 have also been associated with hypoperfusion [14] and increased mortality following trauma [15], and with the development of AKI following cardiac surgery in patients [16]. In rodents, hemorrhagic shock reduced the expression of Tie2 [10, 17] and direct suppression of Tie2 in mice resulted in vascular leakage [18]. Due to its key function in the regulation of endothelial barrier function, targeting Tie 2 has been proposed as a promising strategy to improve outcome of critically ill patients [12]. In line with this hypothesis, we previously reported that targeting Tie2 with vasculotide, a Tie2 agonist, restored cremaster perfusion and reduced microvascular leakage in a rat model of hemorrhagic shock and fluid resuscitation [10]. Additionally, in a murine model of ischemiareperfusion injury, treatment with vasculotide protected renal perfusion, reduced renal edema formation and improved survival [19], proposing a possible application for vasculotide in the treatment of AKI following hemorrhagic shock. 
In the present study, we therefore investigated the effect of hemorrhagic shock and fluid resuscitation on renal perfusion and function and studied whether activation of Tie2, in addition to fluid resuscitation, restores renal perfusion and function following hemorrhagic shock and fluid resuscitation in rats.

\section{Methods}

\section{Animals and experimental set-up}

All procedures were approved by the Institutional Animal Care and Use Committee of the VU University, the Netherlands (Animal welfare number: ANES 13-03A2), and conducted following the European Convention for the Protection of Vertebrate Animals used for Experimental and Other Scientific Purposes and the ARRIVE guidelines on animal research [20]. Male Wistar rats of 350-400 g (Charles River Laboratories, Brussels, Belgium) were housed in a temperature-controlled room (12/12 h day/night cycle, $20-23{ }^{\circ} \mathrm{C}, 40-60 \%$ humidity) with food and water ad libitum. Rats underwent hemorrhagic shock with fluid resuscitation and were randomized and treated blindly with vasculotide (Vasomune Therapeutics, Toronto, Canada) $(n=14)$ or phosphate buffered saline (PBS, Sigma-Aldrich, Zwijndrecht, The Netherlands) as control $(\mathrm{n}=15)$. Renal and cremaster perfusion measurements were performed directly after surgical preparation (baseline), $30 \mathrm{~min}$ after start of shock induction when a mean arterial pressure (MAP) of $30 \mathrm{mmHg}$ was reached, $1 \mathrm{~h}$ after start of shock induction and 0,5, 1, 2, 3 and $4 \mathrm{~h}$ after start of fluid resuscitation (Fig. 1a). Blood gas and hematocrit levels were determined at baseline, $1 \mathrm{~h}$ after start of shock induction and 1, 2, 3 and $4 \mathrm{~h}$ after start of fluid resuscitation.

To exclude a possible effect of microbubbles on the endothelium, a separate group of rats $(n=7)$ was included in which hemorrhagic shock was induced and only cremaster perfusion measurements were performed (data in supplementary file). Normal saline was given on top of standard fluid resuscitation in comparable volumes as the microbubbles to standardize the protocol.

\section{Anesthesia and surgical preparation}

For surgery, rats were anesthetized with $4 \%$ isoflurane (Ivax Farma, Haarlem, The Netherlands) in a plastic box filled with $100 \%$ oxygen. Following endotracheal intubation with a 16G catheter (Venflon Pro, Becton Dickinson, Helsingborg, Sweden), lungs were mechanically ventilated throughout the complete experiment (UMV-03, UNO Roestvaststaal BV, Zevenaar, The Netherlands) with a positive end-expiratory pressure of $1-2 \mathrm{~cm} \mathrm{H}_{2} \mathrm{O}$, a respiratory rate of $\sim 65$ breaths/min, a tidal volume of $\sim 10 \mathrm{ml} /$ $\mathrm{kg}$ and $1.5-2.0 \%$ isoflurane in oxygen-enriched air $\left(40 \% \mathrm{O}_{2} / 60 \% \mathrm{~N}_{2}\right)$. Respiratory rate was adjusted to maintain $\mathrm{pH}$ and partial pressure of carbon dioxide within physiological limits. The body temperature was continuously measured and maintained stable between $36.5{ }^{\circ} \mathrm{C}$ and $37.5{ }^{\circ} \mathrm{C}$ using a temperature controller (TC-1000 Rat, CWe Inc., United States). A 22G catheter (Venflon Pro, Becton Dickinson, Helsingborg, Sweden) was placed in the caudal (tail) artery for continuous measurements of arterial blood pressure. For cremaster microcirculatory perfusion measurements, the left cremaster muscle was isolated under warm saline superfusion, spread out on a heated platform $\left(34{ }^{\circ} \mathrm{C}\right)$ and covered with gas impermeable plastic film (Saran wrap) 


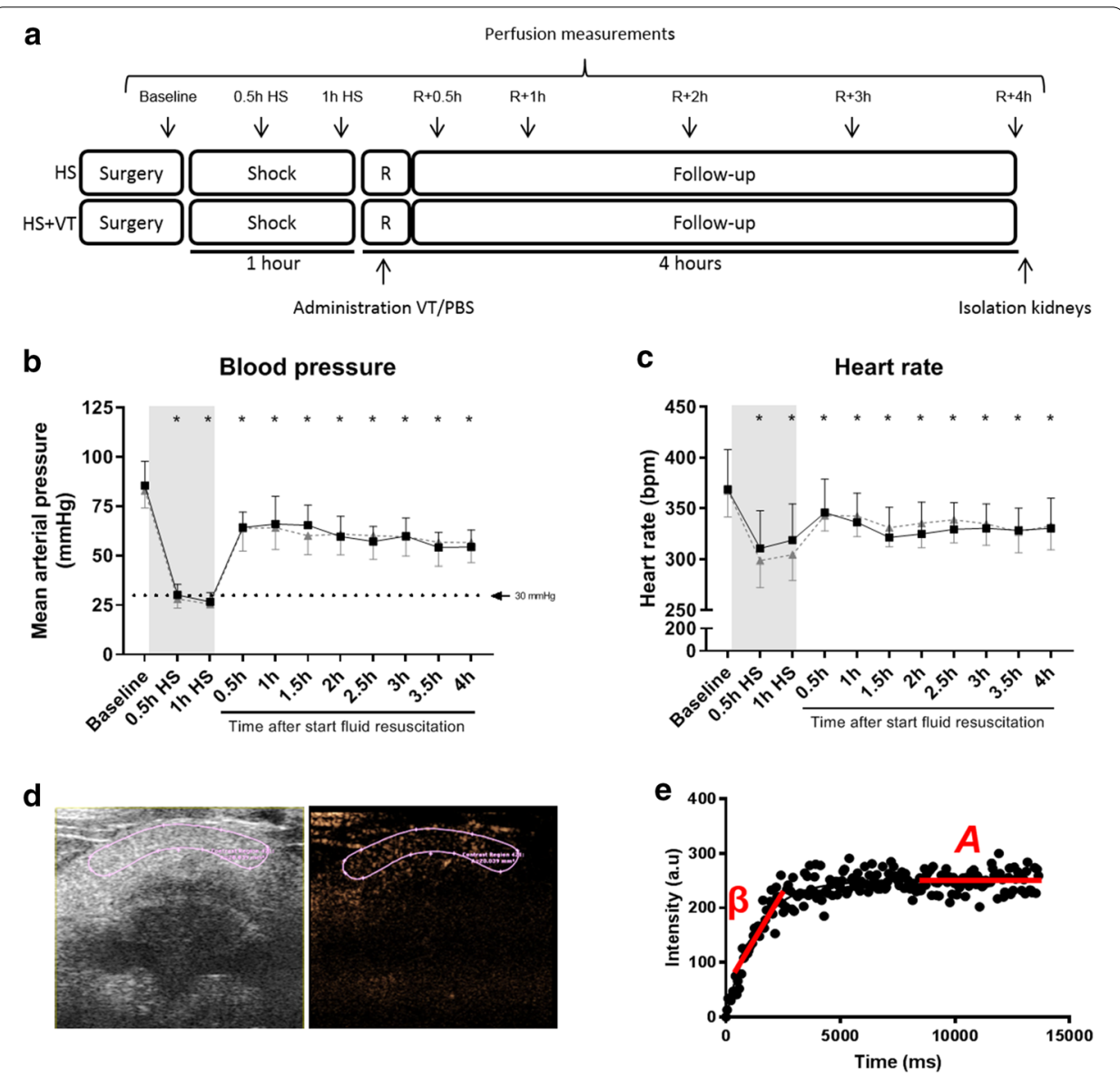

Fig. 1 Experimental protocol. Schematic overview of experimental protocol (a). Hemorrhagic shock was induced by pressure-controlled blood withdrawal, and mean arterial pressure (MAP) was maintained for $1 \mathrm{~h}$ at $30 \mathrm{mmHg}$ (shock). After $1 \mathrm{~h}$ of shock, animals were resuscitated with fluids (R), which was paralleled by administration of vasculotide (VT) as treatment or PBS as control, and monitored for 4 consecutive hours (b, c). Renal and cremaster perfusion measurements were performed directly after the surgical preparation (baseline), 30 min after shock induction $(0.5 \mathrm{~h} \mathrm{HS}), 1 \mathrm{~h}$ after shock induction ( $1 \mathrm{~h} \mathrm{HS})$, and $30 \mathrm{~min}(\mathrm{R}+0.5 \mathrm{~h})$, $1 \mathrm{~h}(\mathrm{R}+1 \mathrm{~h}), 2 \mathrm{~h}(\mathrm{R}+2 \mathrm{~h}), 3 \mathrm{~h}(\mathrm{R}+3 \mathrm{~h})$ and $4 \mathrm{~h}(\mathrm{R}+4 \mathrm{~h})$ after start of fluid resuscitation. Plasma was collected at baseline and before killing ( $4 \mathrm{~h}$ after starting fluid resuscitation). Rats were killed and kidneys were isolated for additional molecular analyses and determination of edema formation. d, e An example of renal perfusion analysis. Regions of interest were drawn in the cortex of the kidney (d). The estimate of perfusion was calculated as the product of microvascular blood volume $A$ and microvascular filling velocity $\beta$ (e). Two-way ANOVA with Bonferroni post hoc analyses, ${ }^{*} \mathrm{P}<0.05 \mathrm{HS}$ group compared to baseline; ${ }^{*} \mathrm{P}<0.05 \mathrm{HS}+\mathrm{VT}$ vs. HS group. Data represent mean $\pm S D, n=13$

as previously described $[10,21,22]$. The right femoral artery was cannulated with a 20G catheter (Arterial Cannula, Becton Dickinson, Helsingborg, Sweden) for blood withdrawal, blood gas analyses (ABL80, radiometer, Copenhagen, Denmark) and hematocrit measurements. The right jugular vein was catheterized with a $22 \mathrm{G}$ catheter (Venflon Pro, Becton Dickinson, Helsingborg, Sweden) for administration of the drugs and infusion of Ringer's lactate and shed blood, as well as infusion of microbubbles for renal perfusion measurements. All catheter insertions were preceded by local application of $1 \%$ lidocaine. Fentanyl $(1.25-2.50 \mu \mathrm{g})$ was administered via the caudal artery for additional analgesia every 20-30 min throughout the experiment. Arterial blood pressure, central venous pressure, ECG and heart rate were continuously 
recorded using PowerLab software (PowerLab 8/35, Chart 8.0; ADInstruments Pty, Ltd., Castle Hill, Australia).

\section{Hemorrhagic shock and fluid resuscitation}

Hemorrhagic shock was induced as previously described [10] by withdrawing blood with from the right femoral artery until a MAP of $30 \mathrm{mmHg}$ was reached and maintained for $1 \mathrm{~h}$ either by withdrawal of blood or reinfusion of heparinized shed blood. Rate of blood withdrawal started at $0.8 \mathrm{ml} / \mathrm{min}$ until MAP of $50 \mathrm{mmHg}$ was reached and was subsequently lowered to $0.2 \mathrm{ml} / \mathrm{min}$. After $1 \mathrm{~h}$ of hemorrhagic shock, rats were resuscitated with Ringer's lactate (Fresenius Kabi, Zeist, The Netherlands; $1 \times$ volume of withdrawn blood) and shed blood (preserved in a syringe with 200 UI heparin (LEO Pharma, Amsterdam, The Netherlands)) with a reinfusion rate of $0.7 \mathrm{ml} / \mathrm{min}$ until baseline levels of MAP were regained. To mimic the clinical setting, a fixed-dose of $200 \mathrm{ng}$ vasculotide in $100 \mu \mathrm{l}$ PBS or $100 \mu \mathrm{l}$ PBS alone as control was administered intravenously between the "pre-hospital" phase (i.e., resuscitation with Ringer's lactate) and the "in-hospital" phase (i.e., resuscitation with shed blood). Optimal treatment concentration was based on dose-response experiments and previously performed experiments by our group [10, 22] (Additional file 1: Fig. S1).

Rats were monitored for 4 consecutive hours in which MAP was maintained $>50 \mathrm{mmHg}$ by infusion of residual shed blood and subsequently Ringer's lactate with an infusion rate of $0.2 \mathrm{ml} / \mathrm{min}$. After killing, the right kidney was used for edema formation determined by wet/dry weight ratio. The left kidney was snap-frozen in liquid nitrogen and stored at $-80{ }^{\circ} \mathrm{C}$ for further analyses.

\section{Renal perfusion with contrast echography}

Contrast-enhanced echography (CEUS) was performed as previous described [23-25] with a Vevo 2100 Imaging System and MS 250 Nonlinear Contrast Imaging transducer (VisualSonics Inc, Toronto, Canada). Microbubbles were prepared from perfluorobutane gas and stabilized with a monolayer of distearoyl phosphatidylcholine and polyoxyethylene (PEG) stearate. 1,2-Distearoyl-sn-glycero-3-phosphocholine (DSPC; Avanti Polar Lipids, Alabama, USA) and polyoxyethylene stearate (PEG40; Sigma, St. Louis, MO, USA) were dissolved in glycerol $(10 \mathrm{mg} / \mathrm{mL}$ ) and sonicated (Decon FS200, Decon Ultrasonics Ltd., Sussex, UK) at $40 \mathrm{kHz}$ in an atmosphere of perfluorobutane (F2 Chemicals Ltd., Lancashire, UK) and vials were shaken in a Vialmix at $4500 \mathrm{rpm}$ (Bristol-Myers Squibb Medical Imaging, Massachusetts, USA). As the gas was dispersed in the aqueous phase, microbubbles were formed, which were stabilized with a self-assembled lipid/surfactant monolayer. A Multisizer 3 Coulter Counter (Beckman Coulter Inc., Miami, FL, USA) was used to measure the particle size distribution as well as the number of particles. Microbubbles with a particle range between 1 and $10 \mu \mathrm{m}$ were diluted in degassed saline to a concentration of $2.5 \cdot 10^{9} / \mathrm{ml}$.

For renal perfusion measurements, microbubbles were continuously infused into the jugular vein with a rate of $150 \mu \mathrm{l} / \mathrm{min}$ (during shock with a rate of $100 \mu \mathrm{l} / \mathrm{min}$ due to $30 \%$ reduction in circulating volume) using a syringe pump (World Precision Instruments Germany GmbH, Berlin, Germany) at the predefined time points (Fig. 1a). After two minutes of microbubble infusion, perfusion images were taken from the longitudinal 
plane of the right kidney. A burst of high acoustic power was applied to destroy the microbubbles. Subsequently, images with low acoustic power were acquired to allow contrast replenishment in the kidney. This destruction-replenishment sequence was repeated two times.

Regions of interest were drawn in the renal cortex (Fig. 1d). Signal intensities from the frames after microbubble destruction were corrected for background noise by subtracting the signal intensity of the first frame after microbubble destruction $(Y 0)$. These intensities were then fitted $\left(Y=Y 0+(A-Y 0) \cdot\left(1-\exp ^{(-\beta \cdot x)}\right)\right)$ for calculation of microvascular blood volume $(A)$ and microvascular filling velocity $(\beta)$, which corresponds to the capillary blood exchange rate. The estimate of perfusion was calculated by the product of $A$ and $\beta$ (Fig. 1e). Analyses were performed by an investigator who was blinded for treatment allocation.

\section{Microcirculatory cremaster perfusion with intravital microscopy}

After stabilization of the exposed cremaster muscle for at least $30 \mathrm{~min}$, cremaster microcirculatory perfusion measurements were performed using a $10 \times$ objective on an intravital microscope (AxiotechVario 100HD, Zeiss, Germany) connected to a digital camera (scA640, Basler, Germany) with a final magnification of 640x, as described previously $[10,21,22]$. Three regions of the microvasculature in the cremaster muscle with adequate perfusion quality were selected during baseline. These predefined regions were followed throughout the experiment at predefined time points (Fig. 1a). For perfusion analyses, two vertical lines were drawn in each video screen. The total amount of capillaries per screen was obtained by averaging the counted capillaries crossing the two vertical lines. These small vessels were categorized as continuously perfused, intermittently perfused (blood flow was arrested at least once or flow was reversed), or non-perfused capillaries (vessels without erythrocytes or non-flowing erythrocytes). Analyses were performed by an investigator who was blinded for treatment allocation.

\section{Renal edema}

Renal tissue was harvested at the end of the experiment under terminal anesthesia. Wet tissue was weighed and dried at $70^{\circ} \mathrm{C}$. After $24 \mathrm{~h}$, dry tissue was weighed and renal wet/ dry weight ratio was calculated as estimate relative of tissue water content.

\section{Plasma and urine analyses}

Arterial blood was withdrawn in heparin tubes at baseline and before killing. Blood was centrifuged twice at $4{ }^{\circ} \mathrm{C}\left(10 \mathrm{~min}\right.$ at $4.000 \times g$ at $4{ }^{\circ} \mathrm{C}$ and $15 \mathrm{~min}$ at $10.000 \times g$ at $\left.4{ }^{\circ} \mathrm{C}\right)$ to obtain platelet-free plasma and stored at $-80^{\circ} \mathrm{C}$. Urine samples were obtained upon killing by aspiration from the bladder with a $25 \mathrm{G}$ needle, immediately snap-frozen and stored at $-80{ }^{\circ} \mathrm{C}$. Urine levels of neutrophil gelatinase-associated lipocalin (NGAL) and kidney injury marker-1 (KIM-1) and plasma levels of circulating angiopoietin-1, angiopoietin-2, soluble Tie2 (Cloud-Clone Corporation, Katy, TX, USA), KIM-1 (R\&D systems, Minneapolis, Minnesota, USA), NGAL (Bioporto, Hellerup, Denmark) and creatinine (MyBioSource, San Diego, California, USA) were measured with enzyme-linked immunosorbent assay (ELISA) in accordance to the manufacturer. Levels of circulating proteins were corrected for hematocrit values. 


\section{Protein analyses}

Frozen kidney tissue was homogenized to obtain cellular protein fractions for Western blot analysis as described previously [10,25]. Protein expression of NGAL, total Tie2, VE cadherin, RhoA and Rac-1 was analyzed using anti-lipocalin-2 (NGAL; ab63929, Abcam, USA), anti-Tie2 (AF762, R\&D systems, USA), anti-RhoA (\#2117, Cell Signaling Technology, USA) and anti-Rac-1 (No. 610650, BD Biosciences, USA). Signals were normalized to glyceraldehyde 3-phosphate dehydrogenase (GAPDH; No. 2118, Cell Signaling Technology, USA) for loading control. Immunoblots were quantified by densitometric analysis of films (ImageQuant TL, v8.1, GE Healthcare, USA) by an investigator who was blinded for treatment allocation.

\section{RNA analyses}

Total RNA was extracted from 10-20 mg frozen kidney tissue and isolated using the RNeasy mini kit (Qiagen, Venlo, the Netherlands) as previously described [10, 22]. The RNA concentration and purity were determined using NanoDrop 1000 (NanoDrop Technologies, Wilmington, DE, USA). A total of $1 \mu$ g RNA was transcribed into complementary DNA using an iScript cDNA synthesis kit (Bio-Rad, Veenendaal, the Netherlands) using oligo-dT priming. mRNA abundance was measured using a CFX384 Touch real-time PCR detection system (Bio-Rad, Veenendaal, the Netherlands). The following primers were used for quantitative polymerase chain reaction: Tie2, NGAL, KIM-1, ICAM-1, VCAM-1, E-selectin, P-selectin, RhoA and Rac-1 (Applied Biosystems, Foster City, California, USA). $\Delta \Delta \mathrm{cT}$ values were calculated and mRNA expression levels were normalized to Arbp abundance (Applied Biosystems, Foster City, California, USA).

\section{Histology}

Four-micrometer-thick paraffin sections were stained with periodic acid-Schiff after diastase [26]. Tubular injury, characterized by necrosis, dilation, cast deposition, and loss of brush border, was graded to the extent of corticomedullary region involvement in 10 randomly chosen, non-overlapping fields ( $\times 20$ magnification), on a scale from 0 to 4 , as follows: 0 , absent; 1,0 to $25 \%$; 2,25 to $50 \% ; 3,50$ to $75 \%$; 4,75 to $100 \%$. Total values were expressed as tubular injury scores. The degree of injury was scored by a pathologist specialized in renal pathology who was blinded to group allocation.

\section{Statistical analysis}

Data were expressed as mean \pm SD and analyzed using GraphPad Prism 8.0 (GraphPad Software, USA). At least a reduction in renal perfusion from 240 to $139 \pm 100$ (unit less) and a reduction in cremaster perfusion from 10.1 to $6.9 \pm 1.7$ perfused vessels per recording after hemorrhagic shock were expected, based on pilot experiments and previously published data [10], respectively. With a two-sided significance level $(\alpha)$ of 0.05 and $\beta$ of 0.9 , group sizes of 13 for renal perfusion measurements and 7 for cremaster perfusion measurements were calculated.

The normality distribution of data was calculated using the Shapiro-Wilk test. For data with a normal distribution, differences between groups were examined for 
statistical significance using one-way analysis of variance (ANOVA) followed by Bonferroni post hoc analyses for comparison of multiple groups, or Student's $t$ test for comparison between two groups. Time-dependent differences in the characteristics of the hemorrhagic shock model and in cremaster microcirculatory perfusion measurements between groups were analyzed using a two-way ANOVA with repeated measurements, renal perfusion measurements using a two-way ANOVA without repeated measurements, followed by Bonferroni post hoc analyses. For data that were not normally distributed, differences between groups were examined using Kruskal-Wallis test followed by Dunn's analyses for multiple comparison for comparison of multiple groups, or Mann-Whitney U test for comparison between two groups. $P$ values less than 0.05 were considered statistically significant.

\section{Results}

\section{Hemodynamic values and blood gas analysis}

All hemodynamic values and results of blood gas analysis are presented in Table 1.

In accordance with the experimental protocol, induction of hemorrhagic shock decreased MAP (Fig. 1b, p <0.0001), which was accompanied by a decrease in heart rate (Fig. 1c, p $<0.0001)$. Fluid resuscitation targeted a MAP $>50 \mathrm{mmHg}(p<0.0001)$ and increased heart rate ( $p<0.01 \mathrm{vs.} 1 \mathrm{~h} \mathrm{HS}$ ), however both values did not restore to baseline values $(p<0.0001 \mathrm{R}+0.5 \mathrm{~h}$ vs. baseline). Both variables remained unaltered during the follow-up period compared to baseline values (both $p<0.0001$ vs. baseline).

Table 1 Hemodynamics and blood gas values

\begin{tabular}{|c|c|c|c|c|c|c|c|c|}
\hline \multirow[t]{2}{*}{ Parameter } & \multicolumn{4}{|l|}{ HS } & \multicolumn{4}{|l|}{$\mathrm{HS}+\mathrm{VT}$} \\
\hline & Baseline & $1 \mathrm{~h} \mathrm{HS}$ & $R+1 h$ & $R+4 h$ & Baseline & $1 \mathrm{~h} \mathrm{HS}$ & $R+1 h$ & $R+4 h$ \\
\hline $\begin{array}{l}\text { MAP } \\
\qquad(\mathrm{mmHg})\end{array}$ & $85 \pm 13$ & $27 \pm 5 *$ & $66 \pm 14^{*}$ & $65 \pm 9 *$ & $83 \pm 9$ & $26 \pm 2 *$ & $64 \pm 11 *$ & $57 \pm 10$ * \\
\hline $\begin{array}{l}\text { Heart rate } \\
\text { (BPM) }\end{array}$ & $369 \pm 39$ & $319 \pm 36 *$ & $336 \pm 29 *$ & $330 \pm 30 *$ & $367 \pm 26$ & $304 \pm 25 *$ & $342 \pm 20 *$ & $333 \pm 24$ * \\
\hline $\begin{array}{l}\text { Tempera- } \\
\text { ture }\end{array}$ & $36.4 \pm 0.7$ & $36.0 \pm 0.5$ & $36.3 \pm 0.5$ & $36.2 \pm 0.5$ & $36.7 \pm 0.6$ & $36.1 \pm 0.8 *$ & $36.3 \pm 0.6$ & $36.3 \pm 0.5$ \\
\hline $\begin{array}{l}\text { CVP } \\
\qquad(\mathrm{mmHg})\end{array}$ & $1 \pm 1$ & $2 \pm 1$ & $4 \pm 2 *$ & $6 \pm 2 *$ & $2 \pm 1$ & $2 \pm 1$ & $3 \pm 1 *$ & $5 \pm 1 *$ \\
\hline $\begin{array}{l}\text { Respira- } \\
\text { tory rate } \\
\quad\left(\mathrm{min}^{-1}\right)\end{array}$ & $65 \pm 5$ & $70 \pm 5$ & $75 \pm 5 *$ & $75 \pm 5 *$ & $65 \pm 5$ & $70 \pm 5$ & $75 \pm 5 *$ & $75 \pm 5 *$ \\
\hline $\mathrm{pH}$ & $7.39 \pm 0.07$ & $7.30 \pm 0.04 *$ & $7.32 \pm 0.05 *$ & $7.29 \pm 0.08 *$ & $* \quad 7.39 \pm 0.04$ & $7.31 \pm 0.04$ * & $7.34 \pm 0.04 *$ & $* 7.29 \pm 0.07 *$ \\
\hline $\mathrm{pCO}_{2}(\mathrm{kPa})$ & $5.47 \pm 1.10$ & $5.18 \pm 0.81$ & $6.06 \pm 0.92$ & $4.88 \pm 0.91$ & $5.03 \pm 0.69$ & $5.06 \pm 0.60$ & $5.57 \pm 0.83$ & $5.26 \pm 1.33$ \\
\hline $\begin{array}{l}\mathrm{HCO}_{3}^{-} \\
\quad(\mathrm{mmol} / \mathrm{L})\end{array}$ & $24.1 \pm 1.4$ & $18.5 \pm 2.0$ * & $22.3 \pm 1.6$ * & $17.5 \pm 1.2^{*}$ & $22.7 \pm 2.3$ & $19.1 \pm 1.8$ * & $21.8 \pm 2.1$ * & $17.8 \pm 3.4^{*}$ \\
\hline $\begin{array}{c}\text { Base excess } \\
(\mathrm{mEq} / \mathrm{L})\end{array}$ & $-0.2 \pm 1.0$ & $-6.8 \pm 1.7^{*}$ & $-3.4 \pm 1.5 *$ & $-7.8 \pm 1.3 *$ & $-1.6 \pm 2.0$ & $-6.5 \pm 2.0 *$ & $-3.4 \pm 1.6^{*}$ & $-7.4 \pm 3.0 *$ \\
\hline $\mathrm{pO}_{2}(\mathrm{kPa})$ & $32.9 \pm 8.2$ & $33.7 \pm 5.6$ & $33.9 \pm 5.1$ & $33.5 \pm 4.2$ & $33.5 \pm 7.7$ & $33.5 \pm 5.4$ & $34.1 \pm 5.6$ & $32.1 \pm 5.5$ \\
\hline $\mathrm{sO}_{2}(\%)$ & $99.7 \pm 0.3$ & $99.8 \pm 0.1$ & $99.8 \pm 0.1$ & $99.8 \pm 0.1$ & $99.8 \pm 0.3$ & $99.8 \pm 0.2$ & $99.8 \pm 0.1$ & $99.7 \pm 0.2$ \\
\hline $\begin{array}{l}\text { Hematocrit } \\
\text { (\%) }\end{array}$ & $40 \pm 2$ & $31 \pm 2 *$ & $33 \pm 2 *$ & $24 \pm 6^{*}$ & $39 \pm 4$ & $32 \pm 3^{*}$ & $34 \pm 3 *$ & $26 \pm 8^{*}$ \\
\hline
\end{tabular}

Data are presented as mean $\pm S D$. ${ }^{*} P<0.05$ compared to the baseline value of the corresponding group. No differences were found between vasculotide (VT) and untreated HS rats. HS; hemorrhagic shock group, HS + VT; hemorrhagic shock group treated with vasculotide, $1 \mathrm{~h} \mathrm{HS}$; values measured at $1 \mathrm{~h}$ following start blood withdrawal, $\mathrm{R}+1 \mathrm{~h}$; values measured at $1 \mathrm{~h}$ following start of fluid resuscitation, $\mathrm{R}+4 \mathrm{~h}$; values measured at $4 \mathrm{~h}$ following of start fluid resuscitation, MAP; mean arterial pressure, CVP; central venous pressure, 
Hemorrhagic shock decreased $\mathrm{pH}$, bicarbonate and base excess (all values: $p<0.0001$ vs. baseline). Fluid resuscitation partly restored bicarbonate levels and base excess (both $p<0.0001$ vs. $1 \mathrm{~h} \mathrm{HS}$ ), but this temporarily restoration in the subsequent hours. $\mathrm{pH}$ was not affected by fluid resuscitation and remained altered during the follow-up period ( $p>0.99$ vs. 1 h HS). Hematocrit decreased following hemorrhagic shock and further decreased during fluid resuscitation. $\mathrm{pCO}_{2}, \mathrm{pO}_{2}$, and $\mathrm{sO}_{2}$ remained unaltered during the complete experiment (all values: $p>0.99$ ). Central venous pressure remained unaltered during hemorrhagic shock ( $p=0.50$ vs. baseline), but increased following fluid resuscitation and in the subsequent hours $(p<0.0001$ vs. $1 \mathrm{~h} \mathrm{HS})$.

Vasculotide treatment did not affect MAP, heart rate, central venous pressure, hematocrit or blood gas values (all values: $p>0.99$ ).

\section{Cremaster perfusion assessed with intravital microscopy}

In the cremaster muscle, hemorrhagic shock decreased the number of continuously perfused vessels (Fig. 2a: from $12 \pm 2$ (baseline) to $5 \pm 2$ ( $1 \mathrm{~h} \mathrm{HS}$ ) perfused vessels/ recording, $p<0.0001$ ) and increased the number of non-perfused vessels (Fig. 2b: from $4 \pm 1$ (baseline) to $10 \pm 1$ ( $1 \mathrm{~h} \mathrm{HS}$ ) non-perfused vessels/recording $p<0.0001$ ). Both parameters were partly restored by fluid resuscitation, but did not reach baseline values $(\mathrm{R}+0.5 \mathrm{~h}: 9 \pm 2$ perfused vessels/recoding $p=0.0001 ; 7 \pm 3$ non-perfused vessels/recording $p<0.0001$ vs $1 \mathrm{~h} H S$ ), and remained stable during the subsequent hours ( $\mathrm{R}+4 \mathrm{~h}: 7 \pm 2$ perfused vessels/recording $p=0.10 ; 8 \pm 2$ non-perfused vessels/ recording $p=0.35$, vs. $\mathrm{R}+0.5 \mathrm{~h}$ ). Hemorrhagic shock resulted in an increase in intermittently perfused vessels (Fig. 2c: $p<0.001$, vs. baseline), which was partly corrected
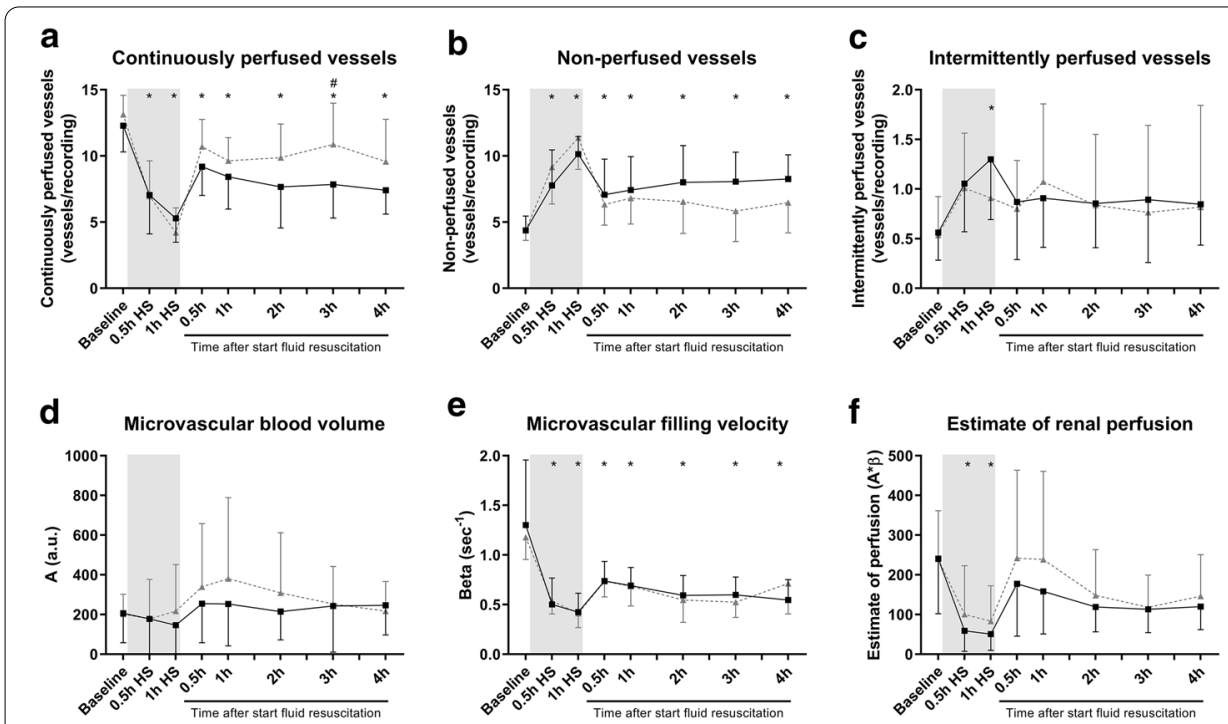

e
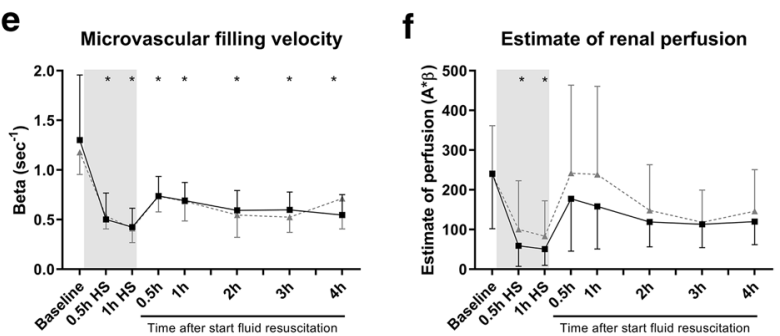

Fig. 2 Cremaster and renal perfusion following hemorrhagic shock and fluid resuscitation. Continuously perfused vessels (a), non-perfused (b) and intermittently perfused vessels (c) in rat cremaster muscle using intravital microscopy. Renal microvascular blood volume $A$ (d), microvascular filling velocity $\beta$ (e) and estimate of renal perfusion $\left(A^{*} \beta ; \mathbf{f}\right)$ as assessed by contrast-enhanced ultrasound echography in rats during and after hemorrhagic shock and fluid resuscitation as control (HS; black line) or with vasculotide treatment (HS +VT; grey dotted line). Two-way ANOVA with Bonferroni post hoc analyses, ${ }^{*} \mathrm{P}<0.05 \mathrm{HS}$ group compared to baseline; ${ }^{*} P<0.05 \mathrm{HS}+\mathrm{VT}$ vs. HS group. Data represent mean $\pm S D, n=13$ 
by fluid resuscitation ( $p=0.15, \mathrm{R}+0.5 \mathrm{~h}$ vs. $1 \mathrm{~h} \mathrm{HS}$ ) and remained stable during subsequent hours $(p>0.99, \mathrm{R}+4 \mathrm{~h}$ vs. $\mathrm{R}+0.5 \mathrm{~h})$.

Treatment with vasculotide restored cremaster perfusion compared to untreated animals (Table 2). This was reflected by a significant increase in the number of perfused vessels at $3 \mathrm{~h}$ following fluid resuscitation ( $\mathrm{R}+3 \mathrm{~h}: 11 \pm 3$ vs $8 \pm 3, p<0.05$, HS + VT vs. untreated HS), but not at other time points $(\mathrm{R}+0.5 p>0.99, \mathrm{R}+1 \mathrm{~h}$ $p>0.99, \mathrm{R}+2 \mathrm{~h} p=0.20, \mathrm{R}+4 \mathrm{~h} p=0.22$, vs untreated HS). No significant differences between groups were found in the number of intermittently perfused or non-perfused vessels, but treatment with vasculotide tended to reduce the number of non-perfused vessels at $3 \mathrm{~h}$ following start of fluid resuscitation ( $p=0.11$, vs. untreated HS rats).

Table 2 Cremaster perfusion and renal perfusion data

\begin{tabular}{|c|c|c|c|c|c|c|c|c|c|}
\hline \multirow[t]{2}{*}{ Parameter } & \multirow[t]{2}{*}{ Group } & \multicolumn{8}{|c|}{ Time point } \\
\hline & & Baseline & $0.5 \mathrm{~h} \mathrm{HS}$ & $1 \mathrm{~h} \mathrm{HS}$ & $\mathrm{R}+0.5 \mathrm{~h}$ & $R+1 h$ & $R+2 h$ & $R+3 h$ & $R+4 h$ \\
\hline \multicolumn{10}{|c|}{ Cremaster perfusion } \\
\hline \multirow[b]{2}{*}{$\begin{array}{l}\text { Continu- } \\
\text { ously } \\
\text { per- } \\
\text { fused } \\
\text { vessels } \\
\text { (ves- } \\
\text { sels/ } \\
\text { record- } \\
\text { ing) }\end{array}$} & HS & $12 \pm 2$ & $7 \pm 3^{*}$ & $5 \pm 2^{*}$ & $9 \pm 2^{*}$ & $8 \pm 2^{*}$ & $8 \pm 3^{*}$ & $8 \pm 3^{*}$ & $7 \pm 2^{*}$ \\
\hline & $H S+V T$ & $13 \pm 1$ & $7 \pm 3^{*}$ & $4 \pm 2^{*}$ & $11 \pm 2^{*}$ & $10 \pm 2^{*}$ & $10 \pm 3^{*}$ & $11 \pm 3^{*} \wedge$ & $10 \pm 3^{*}$ \\
\hline \multirow[b]{2}{*}{$\begin{array}{l}\text { Intermit- } \\
\text { tently } \\
\text { per- } \\
\text { fused } \\
\text { vessels } \\
\text { (ves- } \\
\text { sels/ } \\
\text { record- } \\
\text { ing) }\end{array}$} & $\mathrm{HS}$ & $0.6 \pm 0.3$ & $1.0 \pm 0.5$ & $1.3 \pm 0.6^{*}$ & $0.9 \pm 0.6$ & $0.9 \pm 0.5$ & $0.9 \pm 0.4$ & $0.9 \pm 0.6$ & $0.8 \pm 0.4$ \\
\hline & $\mathrm{HS}+\mathrm{VT}$ & $0.5 \pm 0.4$ & $1.0 \pm 0.6$ & $0.9 \pm 0.4$ & $0.8 \pm 0.5$ & $1.0 \pm 0.8$ & $0.8 \pm 0.7$ & $0.8 \pm 0.9$ & $0.8 \pm 1.0$ \\
\hline \multirow[b]{2}{*}{$\begin{array}{l}\text { Non-per- } \\
\text { fused } \\
\text { vessels } \\
\text { (ves- } \\
\text { sels/ } \\
\text { record- } \\
\text { ing) }\end{array}$} & $\mathrm{HS}$ & $4 \pm 1$ & $8 \pm 3^{*}$ & $10 \pm 1^{*}$ & $7 \pm 3^{*}$ & $7 \pm 3^{*}$ & $8 \pm 3^{*}$ & $8 \pm 2^{*}$ & $8 \pm 2^{*}$ \\
\hline & $\mathrm{HS}+\mathrm{VT}$ & $4 \pm 1$ & $9 \pm 3^{*}$ & $11 \pm 2^{*}$ & $6 \pm 2^{*}$ & $7 \pm 2^{*}$ & $7 \pm 2^{*}$ & $6 \pm 2^{*}$ & $6 \pm 2^{*}$ \\
\hline \multicolumn{10}{|c|}{ Renal perfusion } \\
\hline \multirow{2}{*}{$\begin{array}{l}\text { Microvas- } \\
\text { cular } \\
\text { blood } \\
\text { volume } \\
\text { A (a.u.) }\end{array}$} & HS & $206 \pm 149$ & $178 \pm 258$ & $146 \pm 149$ & $254 \pm 196$ & $253 \pm 211$ & $215 \pm 142$ & $243 \pm 233$ & $246 \pm 149$ \\
\hline & $\mathrm{HS}+\mathrm{VT}$ & $201 \pm 101$ & $178 \pm 199$ & $217 \pm 234$ & $340 \pm 318$ & $380 \pm 408$ & $309 \pm 302$ & $253 \pm 190$ & $217 \pm 149$ \\
\hline \multirow{2}{*}{$\begin{array}{l}\text { Microvas- } \\
\text { cular } \\
\text { filling } \\
\text { velocity } \\
B\left(s^{-1}\right)\end{array}$} & $\mathrm{HS}$ & $1.3 \pm 0.7$ & $0.5 \pm 0.3^{*}$ & $0.4 \pm 0.2^{*}$ & $0.7 \pm 0.2^{*}$ & $0.7 \pm 0.8^{*}$ & $0.6 \pm 0.2^{*}$ & $0.6 \pm 0.2^{*}$ & $0.5 \pm 0.2^{*}$ \\
\hline & $\mathrm{HS}+\mathrm{VT}$ & $1.2 \pm 0.2$ & $0.5 \pm 0.1^{*}$ & $0.4 \pm 0.1^{*}$ & $0.7 \pm 0.2^{*}$ & $0.7 \pm 0.2^{*}$ & $0.5 \pm 0.2^{*}$ & $0.5 \pm 0.2^{*}$ & $0.7 \pm 0.3^{*}$ \\
\hline \multirow{2}{*}{$\begin{array}{c}\text { Estimate } \\
\text { of per- } \\
\text { fusion }\end{array}$} & $\mathrm{HS}$ & $241 \pm 139$ & $59 \pm 52^{*}$ & $51 \pm 41^{*}$ & $177 \pm 131$ & $158 \pm 107$ & $119 \pm 63$ & $113 \pm 59$ & $120 \pm 58$ \\
\hline & $\mathrm{HS}+\mathrm{VT}$ & $234 \pm 122$ & $100 \pm 122^{*}$ & $83 \pm 89^{*}$ & $242 \pm 222$ & $238 \pm 222$ & $148 \pm 115$ & $118 \pm 81$ & $146 \pm 105$ \\
\hline
\end{tabular}

Data presented as mean $\pm S D$. ${ }^{*} P<0.05$ compared to baseline value of the corresponding group. $\wedge P<0.05$ vasculotide effect, compared to the same time point of the untreated HS group. HS; hemorrhagic shock group, HS + VT; hemorrhagic shock group treated with vasculotide. Time points represent $0.5 \mathrm{~h}$ following start of blood withdrawal $(0.5 \mathrm{~h} \mathrm{HS}), 1 \mathrm{~h}$ following start of blood withdrawal $(1 \mathrm{~h} \mathrm{HS})$ and $0.5 \mathrm{~h}(\mathrm{R}+0.5 \mathrm{~h}), 1 \mathrm{~h}(\mathrm{R}+1 \mathrm{~h}), 2 \mathrm{~h}(\mathrm{R}+2 \mathrm{~h}), 3 \mathrm{~h}(\mathrm{R}+3 \mathrm{~h})$ and $4 \mathrm{~h}(\mathrm{R}+4 \mathrm{~h})$ following start of fluid resuscitation 


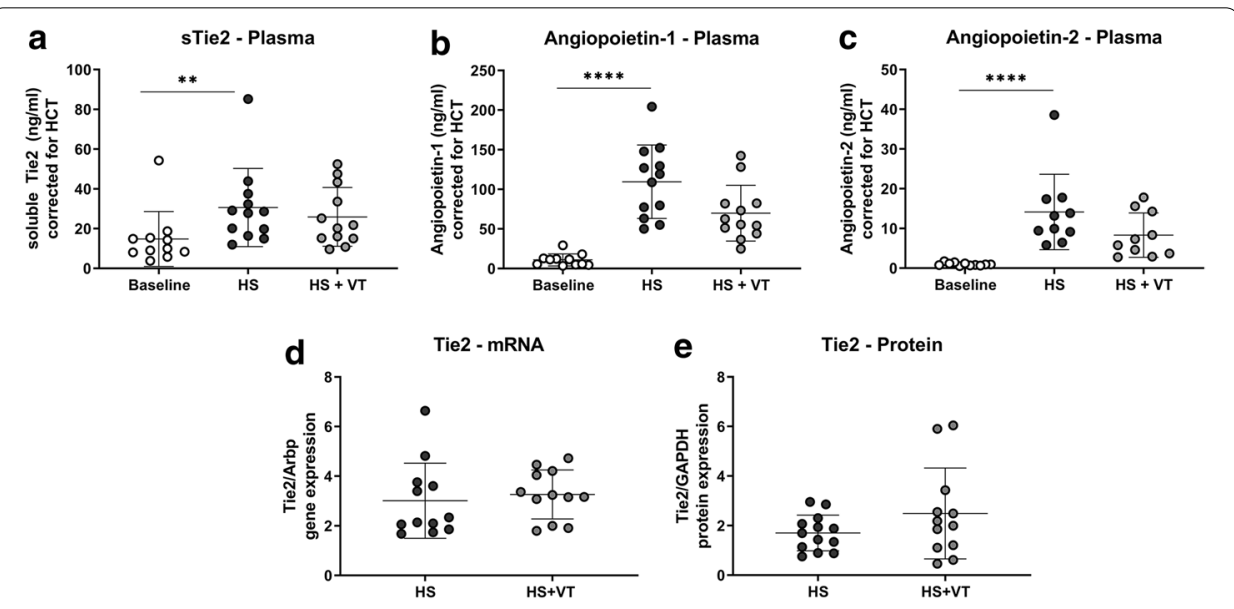

Fig. 3 Expression levels of the angiopoietin/Tie2 system. Plasma levels of soluble Tie2 (a), angiopoietin-1 (b) and angiopoietin-2 (c), measured at baseline (white circles) and following hemorrhagic shock and fluid resuscitation (HS; black circles, HS +VT; grey circles). Renal gene expression of Tie2 (d) and renal protein expression of total Tie2 (e) measured at $4 \mathrm{~h}$ after fluid resuscitation (HS; black circles, HS + VT; grey circles). Data represent mean \pm SD. Plasma: Kruskal-Wallis with Dunn's analyses. Gene and protein expression: Student's T-test. ${ }^{*} \mathrm{P}<0.05 \mathrm{HS}$ group compared to baseline; ${ }^{\mathrm{P}} \mathrm{P}<0.05 \mathrm{HS}+\mathrm{VT}$ vs. HS group. VT; vasculotide

\section{Renal perfusion assessed with contrast echography}

Renal microvascular blood volume $(A)$ was not affected by hemorrhagic shock nor fluid resuscitation (Fig. 2d; $246 \pm 149$ vs $206 \pm 149$ a.u. $p>0.99, \mathrm{R}+4 \mathrm{~h}$ vs baseline). Induction of hemorrhagic shock decreased microvascular filling velocity $(\beta$; Fig. $2 \mathrm{e}$; from baseline: $1.3 \pm 0.7$ to $1 \mathrm{~h}$ HS: $0.4 \pm 0.2 \mathrm{~s}^{-1}, p<0.0001$ ), which partly restored by fluid resuscitation $\left(\mathrm{R}+0.5 \mathrm{~h}: 0.7 \pm 0.2 \mathrm{~s}^{-1} p<0.05\right)$ and remained unaltered in the subsequent hours $\left(\mathrm{R}+4 \mathrm{~h}: 0.5 \pm 0.2 \mathrm{~s}^{-1} p>0.99\right.$ vs $\left.\mathrm{R}+0.5 \mathrm{~h}\right)$. Estimate of renal perfusion decreased

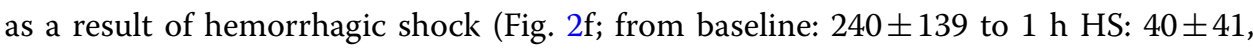
$p<0.001)$. Renal perfusion was only partly restored by fluid resuscitation $(\mathrm{R}+0.5 \mathrm{~h}$ : $177 \pm 131, p=0.07)$, and remained unaltered in the consecutive hours $(\mathrm{R}+4 \mathrm{~h}: 120 \pm 58$, $p>0.99$ vs $\mathrm{R}+0.5 \mathrm{~h})$.

Treatment with vasculotide did not affect microvascular blood volume, microvascular filling velocity nor renal perfusion (all $p>0.99$ ) compared to untreated HS rats (Table 2).

\section{Edema formation and fluid requirements}

Treatment with vasculotide had no significant effect on renal edema formation as assessed by wet/dry ratios $(4.97 \pm 0.4$ vs. $5.35 \pm 0.64, p=0.15)$. Similar amounts of blood were withdrawn to induce hemorrhagic shock in vasculotide-treated HS animals and untreated HS animals ( $6.9 \pm 1.2$ vs. $6.8 \pm 1.2 \mathrm{ml} ; p>0.99)$. Also, no differences were found in resuscitation fluid volumes to reach baseline values $(7.3 \pm 2.5$ vs. $7.5 \pm 2.8 \mathrm{ml}$; $p>0.99$ ) or total resuscitation fluid volume between vasculotide-treated HS animals and untreated HS animals (21.5 \pm 11.5 vs. $20.8 \pm 8.2 \mathrm{ml} ; p>0.99)$.

\section{Angiopoietin/Tie2 and inflammatory signaling}

Hemorrhagic shock and fluid resuscitation increased circulating soluble Tie2 (Fig. 3a, $\mathrm{p}<0.01$ ), angiopoietin-1 (Fig. 3b, p<0.0001) and angiopoietin-2 (Fig. 3c, p<0.0001) levels compared to baseline values. Treatment with vasculotide did not affect soluble Tie2 levels $(p>0.99)$, renal Tie 2 mRNA levels (Fig. $3 d, p=0.26)$, renal Tie2 protein expression 
levels (Fig. 3e, supplemental Fig. 2, $p=0.41)$, circulating angiopoietin-2 levels $(p=0.52)$ or circulating angiopoietin-1 levels $(p=0.29)$ compared to untreated HS rats. Additionally, treatment with vasculotide did not affect mRNA levels of RhoA and Rac-1, downstream targets of the angiopoietin/Tie2 system (Additional file 1: Figs. S2, S3; mRNA expression; Rac-1, $p=0.51$; RhoA, $p=0.58$; protein expression; Rac-1, $p=0.78$; RhoA, $p=0.28)$ compared to untreated animals. Moreover, treatment with vasculotide did not affect renal gene expression of cell endothelial cell adhesion molecules; ICAM-1, VCAM-1, P-selectin and E-selectin (Additional file 1: Fig. S4; ICAM-1, $\mathrm{p}=0.59$; VCAM$1, p=0.42$; E-selectin, $p=0.57$; P-selectin, $p=0.17$ ).

Increased circulating angiopoietin-2 levels positively associated with increased renal edema formation at $4 \mathrm{~h}$ after start of resuscitation $(\mathrm{r}=0.82, p<0.0001)$. No relation was found between increased circulating angiopoietin-1 levels and renal edema formation $(\mathrm{r}=0.009, p=0.97)$ or soluble Tie2 levels and renal edema formation $(\mathrm{r}=0.18, p=0.42)$.

\section{Renal injury}

Hemorrhagic shock and fluid resuscitation increased circulating NGAL (Fig. 4a, p < 0.05), KIM-1 (Fig. 4b, p<0.01) and creatinine (Fig. 4c, p<0.05) levels compared to baseline values. Treatment with vasculotide did not affect circulating NGAL (Fig. 4a, $\mathrm{p}=0.27$ ), KIM-1 (Fig. 4b, $\mathrm{p}=0.78$ ) or creatinine (Fig. 4c, $\mathrm{p}>0.99$ ) levels, nor did it affect urinary levels of NGAL (Fig. $4 \mathrm{~d}, \mathrm{p}=0.50$ ) or KIM-1 (Fig. 4e, $\mathrm{p}=0.81$ ) compared to untreated animals. In renal tissue, treatment with vasculotide did not affect mRNA expression levels of NGAL (Fig. 4f, $\mathrm{p}=0.26$ ) or KIM-1 (Fig. $4 \mathrm{~g}, \mathrm{p}=0.96$ ), or protein expression levels of NGAL (Fig. 4h, supplemental Fig. 4, $p=0.41$ ), measured at $4 \mathrm{~h}$ after fluid resuscitation and compared to untreated HS rats. The degree of renal damage was similar in both groups (Fig. 4i-k), as assessed via histopathological analysis.

\section{Effect of microbubbles}

In most variables, no differences were found in hemodynamics (Additional file 1: Fig. S5A-F) and cremaster perfusion (Additional file 1: Fig. S5G, H) between HS rats that did, or did not receive microbubbles. However, rats that did not receive microbubbles had increased levels of bicarbonate at $2 \mathrm{~h}$ after starting fluid resuscitation $(22.4 \pm 0.4$ vs $19.7 \pm 1.4 \mathrm{mmol} / \mathrm{L}, p<0.01)$ and increased levels of base excess at $2 \mathrm{~h}(-3.4 \pm 1.4$ vs $-5.4 \pm 1.4 \mathrm{mEq} / \mathrm{L}, p<0.05)$ and $3 \mathrm{~h}$ after starting fluid resuscitation $(-3.5 \pm 1.8$ vs $6.0 \pm 1.0 \mathrm{mEq} / \mathrm{L}, p<0.01)$ compared to HS rats that received microbubbles. However, these differences abolished over time as at $4 \mathrm{~h}$ after starting fluid resuscitation no differences were observed. Also, no differences in renal wet/dry ratios were found between HS control rats receiving microbubbles and HS control rats that did not receive microbubbles (Additional file 1: Fig. S5I, $\mathrm{p}=0.14$ ).

\section{Discussion}

In the present study, we showed that hemorrhagic shock impairs renal and cremaster perfusion. The clinical standard therapy with fluid resuscitation only partly restored renal and cremaster perfusion, but could not restore perfusion back to baseline values in both organs. These perfusion disturbances were paralleled by renal injury and an imbalance in key components of the endothelial angiopoietin/Tie2 system. Interestingly, the 

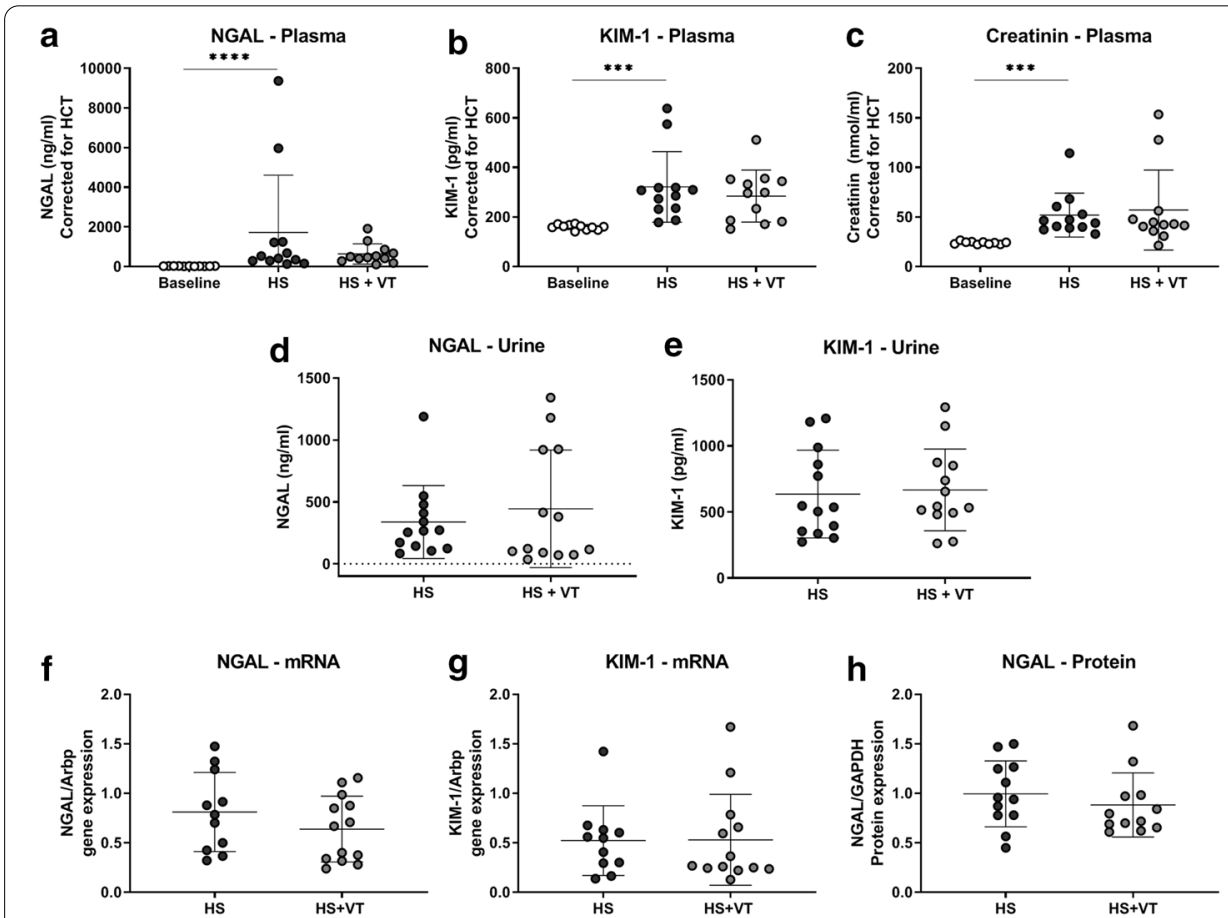

i

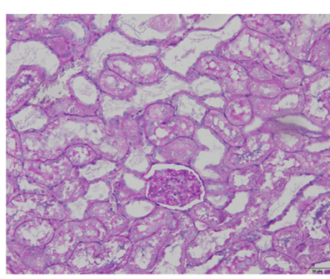

j

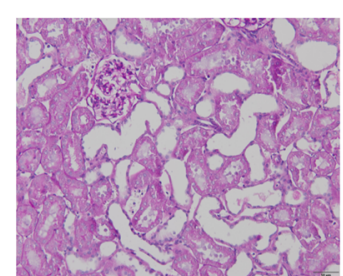

k

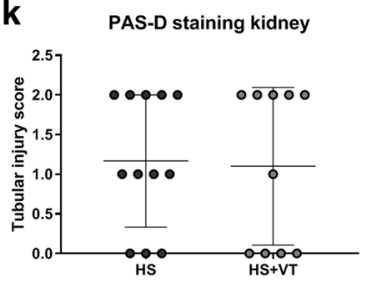

Fig. 4 Expression levels of renal injury markers. Plasma levels of NGAL (a), KIM-1 (b) and creatinine (c), measured at baseline (white circles) and following hemorrhagic shock and fluid resuscitation (HS; black circles, HS +VT; grey circles). Urinary levels of NGAL (d) and KIM-1 (e), measured following hemorrhagic shock and fluid resuscitation (HS; black circles, $\mathrm{HS}+\mathrm{VT}$, grey circles). Renal gene expression of NGAL (f) and KIM-1 $(\mathbf{g})$, and renal protein expression of NGAL (h) measured following hemorrhagic shock and fluid resuscitation $(H S$; black circles, HS +VT; grey circles). Microphotographs (original magnification $\times 20$ ) of PAS-d stained renal tissue sections from untreated HS rats (i) and VT-treated HS rats (j), showing similar degrees of ischemic tubular injury, as evidenced by tubular dilation and loss of brush borders, tubular injury scores represented in graph (k). Data represent mean \pm SD. Plasma: Kruskal-Wallis with Dunn's analyses. Gene and protein expression: Student's T-test. ${ }^{*} \mathrm{P}<0.05 \mathrm{HS}$ group compared to baseline; $\# \mathrm{P}<0.05 \mathrm{HS}+\mathrm{VT}$ vs. HS group. VT vasculotide, NGAL neutrophil gelatinase-associated lipocalin, KIM-1 kidney injury marker-1

proposed relation between elevated angiopoietin-2 levels and organ failure was confirmed in the current study, as increased circulating angiopoietin-2 levels were associated with increased renal edema formation. However, treatment with the Tie 2 agonist vasculotide did not improve renal perfusion, nor did it reduce renal injury. Treatment with vasculotide did temporarily improve cremaster perfusion during fluid resuscitation, indicating biological activity of the compound. Our data suggest that stimulation of Tie2 is not a suitable approach following hemorrhagic shock and fluid resuscitation to improve renal perfusion and function.

Previously, we showed that hemorrhagic shock impaired microcirculatory perfusion in the cremaster muscle in rats, which was accompanied by increased pulmonary and 
renal microvascular leakage [10]. In the present study, we confirmed the detrimental effects of hemorrhagic shock on cremaster microcirculatory perfusion. Additionally, we showed that hemorrhagic shock impaired renal perfusion. Although the available knowledge regarding renal perfusion following hemorrhagic shock is limited, our data are in line with previously performed animal studies. Hemorrhagic shock reduced cortical renal perfusion as determined by IDF microscopy [9] and blood loss $>35 \%$ of circulating volume deteriorated renal perfusion as measured by invasive laser Doppler flowmetry [27]. Here, we show the applicability of a non-invasive imaging technique, contrast-enhanced ultrasonography, which can be used in the clinical setting to determine hemorrhagic shock-induced renal perfusion disturbances [28, 29]. Importantly, the effect of hemorrhagic shock on microcirculatory perfusion in the present study was tissue-specific as renal perfusion was more severely affected by hemorrhagic shock than cremaster perfusion with a reduction in perfusion of $80 \%$ versus $57 \%$, respectively, compared to baseline values. This confirms the vulnerability of the renal vasculature after hemorrhagic shock $[9,30,31]$ and highlights the importance of selective imaging of perfusion in vital organs and the need for interventions that restore kidney perfusion.

To date, general treatment options following hemorrhagic shock aim to restore circulating volume by fluid resuscitation. However, fluid overload can lead to multiple organ failure and worsen outcome [32]. In the current study, we showed that with a nonaggressive fluid resuscitation strategy by targeting $\mathrm{MAP}>50 \mathrm{mmHg}$, renal perfusion is not restored back to baseline levels after HS. Current transfusion protocols target a specific MAP, however, the optimal target MAP is still up for debate [33, 34]. Our study clearly shows that restoration of MAP with a permissive fluid resuscitation strategy does not restore renal perfusion. A hypotensive resuscitation strategy targeting a MAP of $50 \mathrm{mmHg}$ reduces transfusion requirements compared to a target MAP of $65 \mathrm{mmHg}$ [35, 36] and improves survival among trauma patients [37], whereas aggressive fluid resuscitation is known to induce cardiac and pulmonary complications [38]. In contrast, renal perfusion and glomerular filtration appear pressure-dependent below a MAP of $75 \mathrm{mmHg}$, leading to reduced renal oxygenation [39], which might explain the lack of restoration of renal perfusion during fluid resuscitation. In conclusion, we showed that standard fluid resuscitation failed to restore renal and cremaster perfusion, confirming that additional treatment strategies are warranted.

One of the underlying pathological features that may explain the discrepancy between effects on global hemodynamics and tissue perfusion is microvascular leakage. Following hemorrhagic shock and fluid resuscitation, microvascular leakage increases in both kidney and lungs [10]. Especially during fluid resuscitation, microvascular leakage has detrimental effects as it reduces the benefits of fluid therapy [40]. As a consequence of endothelial hyperpermeability, fluids can partially leak to the interstitium, leading to tissue edema. Tissue edema increases diffusion distances, which impairs oxygen delivery and may eventually lead to organ failure as result of tissue hypoperfusion. The angiopoietin/Tie2 system is a key regulator of endothelial permeability. Following hemorrhagic shock and fluid resuscitation, the angiopoietin/Tie2 signaling changes extensively $[8,10$, 17], which is also confirmed in the current study. This detrimental shift towards angiopoietin-2/Tie2 signaling is associated with the development of AKI following trauma 
[15] or cardiac surgery [16], and with negative clinical outcome [15]. Elevated angiopoietin-2 levels have previously been associated with in vitro endothelial hyperpermeability $[11,41]$. In line with this observation, we observed that elevated angiopoietin-2 levels were associated with renal edema formation, proposing angiopoietin- 2 as contributor to or interesting biomarker for the development of kidney injury following hemorrhagic shock. Collectively, we confirmed the angiopoietin/Tie2 system as potential target to reduce microvascular leakage.

In the current study, we targeted Tie 2 with vasculotide to reduce microvascular leakage and thereby improve the effectiveness of fluid resuscitation, as reflected by improvement of microcirculatory perfusion and renal function. Previously performed studies reported the capability of vasculotide to enhance Tie 2 phosphorylation, as determined in rat glomerular endothelial cells [10] and septic mice [43]. Here, we found that treatment with vasculotide temporarily restored cremaster perfusion, but did not affect renal perfusion or renal injury. One possible explanation for this may be the organ-specific expression levels of Tie2, as Tie2 has a relatively low expression pattern in renal tissue compared to pulmonary tissue [42]. Several studies investigated the effect of vasculotide in diverse animal models of critical illness [19, 43, 44]. In septic mice, vasculotide reduced microvascular leakage in lungs [43, 44], but not in kidneys or in the spleen [44]. In contrast with our findings, Rübig et al. reported an improvement in renal perfusion and function following treatment with vasculotide in mice with renal ischemia-reperfusion injury [19]. Differences in outcome may be a function of injury severity, disease model, host animal or timing and dosage of treatment. Unfortunately, increasing the dosage of vasculotide resulted in adverse effects on microcirculatory perfusion as determined in pilot experiments, as reflected by suboptimal microcirculatory perfusion in sham animals. This dose-dependent effect was also confirmed by Kümpers et al., as an increased dosage of vasculotide reduced survival following sepsis compared to a lower dosage [43]. Taken together, treatment with vasculotide was unable to restore renal perfusion and function in the current set-up.

Strengths and limitations The current study is one of the first to assess microcirculatory perfusion in different organs within the same animal due to the use of two imaging techniques. This resulted in the interesting and important finding that the given treatment showed organ-specific efficiency. Second, although renal injury is a known complication following hemorrhagic shock and fluid resuscitation, knowledge regarding the course of renal perfusion during and following hemorrhagic shock was lacking. However, the current study assessed renal injury in a fairly short time frame. Even though all circulating renal injury markers confirmed the development of renal injury, a possible beneficial effect of vasculotide over a longer period cannot be excluded. As there are no specific antibodies available to assess Tie 2 phosphorylation in rat kidney tissue, it was not possible to measure activation of the Tie 2 receptor following vasculotide treatment. However, previous studies confirmed the capability of vasculotide to enhance Tie2 phosphorylation in mice [43] and rat glomerular cell culture [10].

\section{Conclusion}

Hemorrhagic shock attenuated renal and cremaster perfusion in rats, and perfusion in both organs was only partly restored following fluid resuscitation. These perfusion 
disturbances were paralleled by renal injury and an imbalance in key components of the angiopoietin/Tie2 system. Targeting Tie2 using vasculotide did not improve renal perfusion or function, but temporarily restored cremaster perfusion. Our results show that targeting Tie2 using vasculotide is not an appropriate strategy to restore renal perfusion disturbances following hemorrhagic shock. Future studies should focus on targeting the angiopoietin/Tie2 system via a different approach, such as decreasing circulating angiopoietin-2 levels, or could investigate the effect of activation of Tie2 in other affected organs to improve organ failure other than the kidneys.

\begin{abstract}
Abbreviations
AKI: Acute kidney injury; ANOVA: Analysis of variance; CEUS: Contrast-enhanced echography; DSPC: Distearoyl phosphatidylcholine; ELISA: Enzyme-linked immunosorbent assay; GAPDH: Glyceraldehyde 3-phosphate dehydrogenase; HS: Hemorrhagic shock; ICAM-1: Intercellular adhesion molecule 1; MAP: Mean arterial pressure; KIM-1: Kidney injury marker-1; NGAL: Neutrophil gelatinase-associated lipocalin; PAS-D: Periodic acid-Schiff after diastase; PBS: Phosphate buffered saline; PEG: Polyoxyethylene; VCAM-1: Vascular cell adhesion protein 1;VT:Vasculotide.
\end{abstract}

\title{
Supplementary Information
}

The online version contains supplementary material available at https://doi.org/10.1186/s40635-021-00389-5.

Additional file1: Figure S1. Vasculotide dose-dependent efficiency on cremaster perfusion in sham and hemorrhagic shock rats. Figure S2. Raw data of western blot analysis. Figure S3. Expression levels of markers reflecting endothelial barrier function. Figure S4. Expression levels of cell adhesion molecules. Figure S5. Effect of microbubbles on hemodynamic values, cremaster perfusion and renal wet/dry ratio.

\section{Acknowledgements}

Not applicable

\section{Authors' contributions}

Conception and design of research: ALIL, NAMD, PS, MM, CEB. Performed experiments and analyzed data: ALIL, NAMD, EG, JJTHR, CEB. Interpreted results of experiments: ALIL, NAMD, MGV, JJTHR, CEB. Drafted manuscript: ALIL, CEB. All authors read and approved the final manuscript.

\section{Funding}

NAMD has received a Grant (2016T064) from the Dutch Heart Foundation and CSL-Behring (Prof Heimburger Award). CEvdB is supported by the European Society of Anaesthesiology (Research project Grant 2016), the European Society of Intensive Care Medicine (Levi-Montalcini Award 2017), the Dutch Society of Anesthesiology (Young Investigator Grant 2017) and the Dutch Research Council (Veni 2019). For the remaining authors none were declared.

Availability of data and materials

The datasets used and/or analyzed during the current study are available from the corresponding author on reasonable request.

\section{Declarations}

\section{Ethics approval and consent to participate}

All procedures were approved by the Institutional Animal Care and Use Committee of the VU University, the Netherlands (Animal welfare number: ANES 13-03A2), and conducted following the European Convention for the Protection of Vertebrate Animals used for Experimental and Other Scientific Purposes and the ARRIVE guidelines on animal research.

\section{Consent for publication}

Not applicable.

\section{Competing interests}

PVS is listed as inventor on multiple patents related to Vasculotide filed by Sunnybrook Health Sciences Centre and Vasomune Therapeutics, Canada. For the remaining authors none were declared.

\section{Author details}

'Department of Anesthesiology, Experimental Laboratory for Vital Signs, Amsterdam Cardiovascular Sciences, Amsterdam UMC, Vrije Universiteit, De Boelelaan 1117, 1081 HV Amsterdam, The Netherlands. ${ }^{2}$ Department of Physiology, Amsterdam Cardiovascular Sciences, Amsterdam UMC, Vrije Universiteit, Amsterdam, The Netherlands. ${ }^{3}$ Department of Cardiothoracic Surgery, Amsterdam Cardiovascular Sciences, Amsterdam UMC, Vrije Universiteit, Amsterdam, The Netherlands. ${ }^{4}$ Vasomune Therapeutics, Toronto, Canada. ${ }^{5}$ Department of Nephrology, Amsterdam Cardiovascular Sciences, VU University Medical Center, Amsterdam, the Netherlands. ${ }^{6}$ Department of Pathology, Amsterdam Cardiovascular Sciences, Academic Medical Center, University of Amsterdam, Amsterdam, Netherlands. ${ }^{7}$ Department of Pathology 
and Medical Biology, Medical Biology Section, University Medical Center Groningen, Groningen, The Netherlands. ${ }^{8}$ Department of Critical Care Medicine, University Medical Center Groningen, Groningen, The Netherlands. ${ }^{9}$ Department of Intensive Care, Amsterdam UMC, University of Amsterdam, Amsterdam, The Netherlands.

Received: 23 February 2021 Accepted: 21 April 2021

Published online: 17 May 2021

\section{References}

1. Hutchings SD, Naumann DN, Hopkins P et al (2018) Microcirculatory impairment is associated with multiple organ dysfunction following traumatic hemorrhagic shock: The MICROSHOCK Study. Crit Care Med 46(9):e889-e896

2. Harrois A, Libert N, Duranteau J (2017) Acute kidney injury in trauma patients. Curr Opin Crit Care 23(6):447-456

3. Harrois A, Soyer B, Gauss T et al (2018) Prevalence and risk factors for acute kidney injury among trauma patients: a multicenter cohort study. Crit Care 22:344

4. Tachon G, Harrois A, Tanaka S et al (2014) Microcirculatory alterations in traumatic hemorrhagic shock. Crit Care Med 42(6):1433-1441

5. Verma SK, Molitoris BA (2015) Renal endothelial injury and microvascular dysfunction in acute kidney injury. Semin Nephrol 35(1):96-107

6. Legrand M, Mik EG, Balestra GM et al (2010) Fluid resuscitation does not improve renal oxygenation during hemorrhagic shock in rats. Anesthesiology 112(1):119-127

7. Aksu U, Demirci C, Ince C (2011) The pathogenesis of acute kidney injury and the toxic triangle of oxygen, reactive oxygen species and nitric oxide. Contrib Nephrol 174:119-128

8. Yan R, van Meurs M, Popa ER et al (2019) Early heterogenic response of renal microvasculature to hemorrhagic shock/resuscitation and the influence of NF-kB pathway blockade. Shock 51(2):200-212

9. Eguillor JFC, Ferrara G, Edul VSK et al (2020) Effects of Systemic Hypothermia on Microcirculation in Conditions of Hemodynamic Stability and in Hemorrhagic Shock. Shock. https://doi.org/10.1097/SHK.0000000000001616

10. Trieu M, van Meurs M, van Leeuwen ALI (2018) Vasculotide, an angiopoietin-1 mimetic, restores microcirculatory perfusion and microvascular leakage and decreases fluid resuscitation requirements in hemorrhagic shock. Anesthesiology 128(2):361-374

11. van Leeuwen ALI, Naumann DN, Dekker NAM et al (2020) In vitro endothelial hyperpermeability occurs early following traumatic hemorrhagic shock. Clin Hemorheol Microcirc 75(2):121-133

12. Sack KD, Kellum JA, Parikh SM (2020) The angiopoietin-Tie2 pathway in critical illness. Crit Care Clin 36(2):201-216

13. Roviezzo F, Tsigkos S, Kotanidou A et al (2005) Angiopoietin-2 causes inflammation in vivo by promoting vascular leakage. J Pharmacol Exp Ther 314(2):738-744

14. Richter RP, Russell RT, Hu PJ et al (2019) Plasma angiopoietin-2/-1 ratio is elevated and angiopoietin-2 levels correlate with plasma syndecan-1 following pediatric trauma. Shock 52(3):340-346

15. Ganter MT, Cohen MJ, Brohi K et al (2008) Angiopoietin-2, marker and mediator of endothelial activation with prognostic significance early after trauma? Ann Surg 247(2):320-326

16. Jongman RM, Van Klarenbosch J, Molema G et al (2015) Angiopoietin/Tie2 dysbalance is associated with acute kidney injury after cardiac surgery assisted by cardiopulmonary bypass. PLoS ONE 10(8):e0136205

17. van Meurs M, Kurniati NF, Wulfert FM et al (2009) Shock-induced stress induced loss of microvascular endothelial Tie2 in the kidney which is not associated with reduced glomerular barrier function. Am J Physiol Renal Physiol 297:F272-281

18. Ghosh CC, David S, Zhang R et al (2016) Gene control of tyrosine kinase TIE2 and vascular manifestations of infections. Proc Natl Acad Sci U S A 113(9):2472-2477

19. Rübig E, Stypmann J, Van Slyke P et al (2016) The synthetic Tie2 agonist peptide vasculotide protects renal vascular barrier function in experimental acute kidney injury. Sci Rep 25(6):22111

20. Reynolds P, Wall P, van Griensven M et al (2012) Shock supports the use of animal research reporting guidelines. Shock 38(1):1-3

21. Koning NJ, de Lange F, van Meurs M et al (2018) Reduction of vascular leakage by imatinib is associated with preserved microcirculatory perfusion and reduced renal injury in a rat model of cardiopulmonary bypass. $\mathrm{Br} J$ Anaesth 120(6):1165-1175

22. Dekker NAM, van Meurs M, van Leeuwen ALI et al (2018) Vasculotide, an angiopoietin-1 mimetic reduces pulmonary vascular leakage and preserves microcirculatory perfusion during cardiopulmonary bypass in rats. $\mathrm{Br} J$ Anaesth 121(5):1041-1051

23. Boly CA, Eringa EC, Bouwman RA et al (2016) The effect of perioperative insulin treatment on cardiodepression in mild adiposity in mice. Cardiovasc Diabetol 15(1):135

24. Van den Brom CE, Boly CA, Bulte CSE et al (2016) Myocardial perfusion and function are distinctly altered by sevoflurane anesthesia in diet-induced prediabetic rats. J Diabetes Res 2016:5205631

25. van den Brom CE, Bulte CS, Kloeze BM et al (2012) High fat diet-induced glucose intolerance impairs myocardial function, but not myocardial perfusion during hyperaemia: a pilot study. Cardiovasc Diabetol 11:74

26. Roelofs JJ, Rouschop KM, Leemans JC et al (2006) Tissue-type plasminogen activator modulates inflammatory responses and renal function in ischemia reperfusion injury. J Am Soc Nephrol 17(1):131-140

27. Erni D, Banic A, Wheatley AM et al (1995) Haemorrhage during anaesthesia and surgery: continuous measurement of microcirculatory blood flow in the kidney, liver, skin and skeletal muscle. Eur J Anaesthesiol 12(4):423-429 
28. Malhi H, Grant EG, Duddalwar V (2014) Contrast-enhanced ultrasound of the liver and kidney. Radiol Clin North Am 52(6):1177-1190

29. Lin Q, LV F, Luo Y et al (2001) (2015) Contrast-enhanced ultrasound for evaluation of renal trauma during acute hemorrhagic shock: a canine model. J Med Ultrason 42(2):199-205

30. Sutton TA, Fisher CJ, Molitoris BA (2002) Microvascular endothelial injury and dysfunction during ischemic acute renal failure. Kidney Int 62(5):1539-1549

31. Torres Filho I (2017) Hemorrhagic shock and the microvasculature. Compr Physiol 8(1):61-101

32. Claure-Del Granado R, Mehta RL (2016) Fluid overload in the ICU: evaluation and management. BMC Nephrol 17(1):109

33. Forni LG, Joannidis M (2017) Blood pressure deficits in acute kidney injury: not all about the mean arterial pressure? Crit Care 21:102

34. Sato R, Luthe SK, Nasu M (2017) Blood pressure and acute kidney injury. Crit Care 21(1):28

35. Carrick MM, Leonard J, Slone DS et al (2016) Hypotensive resuscitation among trauma patients. Biomed Res Int 2016:8901938

36. Morrison CA, Carrick MM, Norman MA et al (2011) Hypotensive resuscitation strategy reduces transfusion requirements and severe postoperative coagulopathy in trauma patients with hemorrhagic shock: preliminary results of a randomized controlled trial. J Trauma 70(3):652-663

37. Albreiki M, Voegeli D (2018) Permissive hypotensive resuscitation in adult patients with traumatic haemorrhagic shock: a systematic review. Eur J Trauma Emerg Surg 44(2):191-202

38. Cotton BA, Guy JS, Morris JA Jr et al (2006) The cellular, metabolic, and systemic consequences of aggressive fluid resuscitation strategies. Shock 26(2):115-121

39. Skytte Larsson J, Bragadottir G, Redfors B et al (2018) Renal effects of norepinephrine-induced variations in mean arterial pressure after liver transplantation: a randomized cross-over trial. Acta Anaesthesiol Scand 62(9):1229-1236

40. Dilken O, Ergin B, Ince C (2020) Assessment of sublingual microcirculation in critically ill patients: consensus and debate. Ann Transl Med 8(12):793

41. Dekker NAM, van Leeuwen ALI, van Strien WWJ et al (2019) Microcirculatory perfusion disturbances following cardiac surgery with cardiopulmonary bypass are associated with in vitro endothelial hyperpermeability and increased angiopoietin-2 levels. Crit Care 23(1):117

42. Aslan A, van Meurs M, Moser J et al (2017) Organ-specific differences in endothelial permeability-regulating molecular responses in mouse and human sepsis. Shock 48(1):69-77

43. Kumpers P, Gueler F, David S et al (2011) The synthetic tie2 agonist peptide vasculotide protects against vascular leakage and reduces mortality in murine abdominal sepsis. Crit Care 15(5):R261

44. David S, Ghosh CC, Kümpers P et al (2011) Effects of a synthetic PEG-ylated Tie-2 agonist peptide on endotoxemic lung injury and mortality. Am J Physiol Lung Cell Mol Physiol 300(6):L851-862

\section{Publisher's Note}

Springer Nature remains neutral with regard to jurisdictional claims in published maps and institutional affiliations.

\section{Submit your manuscript to a SpringerOpen ${ }^{\circ}$ journal and benefit from:}

- Convenient online submission

Rigorous peer review

- Open access: articles freely available online

- High visibility within the field

Retaining the copyright to your article

Submit your next manuscript at $\boldsymbol{\nabla}$ springeropen.com 